\title{
Energy Management of a Grid-connected High Power Energy Recovery Battery Testing System
}

\begin{abstract}
Ke Zhang**, Bo Long**, Cheol-Jung Yoo ${ }^{\dagger}$, Hye-Min Noh* and Young-Won Chang*
Abstract - Energy recovery battery testing systems (ERBTS) have been widely used in battery manufactures. All the ERBTS are connected in parallel which forms a special and complicated microgrid system, which has the shortcomings of low energy recovery efficiency, complex grid-connected control algorithms issues for islanded detection, and complicated power circuit topology issues. To solve those shortcomings, a DC micro-grid system is proposed, the released testing energy has the priority to be reutilized between various testing system within the local grid, Compared to conventional scheme, the proposed system has the merits of a simplified power circuit topology, no needs for synchronous control, and much higher testing efficiency. The testing energy can be cycleused inside the local micro-grid. The additional energy can be recovered to AC-grid. Numerous experimental comparison results between conventional and proposed scheme are provided to demonstrate the validity and effectiveness of the proposed technique.
\end{abstract}

Keywords: Energy recovery, Battery testing system, Islanded detection, Micro-grid

\section{Introduction}

The development of power accumulator batteries is the key issue for the industrialization of electric vehicles. Battery performance greatly influences the driving mileage and reliability of EVs. Hence, the characteristics of the produced batteries must be evaluated. The common method for battery performance evaluation is charging/discharging test. In order to improve the accuracy of testing current, the power transistors are forced to operate in the linear region with a large power resistance adopted as the load. The discharged energy is totally wasted during this process. According to a latest report from Chinese government, the power consumption can reach up to 736000 thousand kilowatt. The corresponding economic loss of the wasted energy can reach up to 1.18 billion USD.

To solve the above problems, energy recovery battery test systems (ERBTS) have been developed by some companies such as Aerovomental and Bitrode Limited in USA and Arbin and Digatron in Germany. Moreover, control strategies have been researched by us [1-4].

Nowadays, much attention has been focused on how to improve the energy saving efficiency of a single battery testing system, If many ERBTSs are simultaneously used, massive amounts of discharging energy can be saved. However, we found that these instruments have not been

$\dagger$ Corresponding Author: Department of Software Engineering, Chonbuk National University, Jeonju, South Korea.

(cjyoo@jbnu.ac.kr)

* Department of Software Engineering, Chonbuk National University, Jeonju, South Korea. (m01056165534@gmail.com)

** School of Mechanical, Electronic, and Industrial Engineering, University of Electronic Science and Technology of China, Chengdu, Sichuan, China. (pepper@std.uestc.edu.cn)

Received: August 27, 2014; Accepted: February 12, 2016 practically adopted due to the following reasons.

(1) Since the maximum output power of ERBTS can reach $250 \mathrm{~kW}$, the associated instantaneous power input, when interfacing with the $\mathrm{AC}$ grid, might cause an obvious rise and fall of the voltage at the point of common coupling (PCC), the frequency at PCC also can be changed, Moreover, without being properly controlled, it might generate serious harmonic and voltage decrease on the nearby devices sharing the same grid. Because of these unresolved issues, the electric power department inhibits the interfacing of high power ERBTS to the AC-grid.

(2) The conventional battery testing system has much lower energy recovery efficiency, which is due to a fundamental frequency isolation transformer being utilized in the composite power circuit. In addition, the conventional ERBTS is very expensive. For a $200 \mathrm{~kW}$ testing system, the selling price can reach about 24,000 USD.

In recent years, due to its advantages by nature, the DC micro-grid has received extensive attention in power systems. The DC micro-grid system is suitable for use with renewable energy sources, such as photovoltaic (PV) energy, wind power, tidal energy, and geothermal energy. Compared with AC micro-grid, the DC micro-grid system, which features as one stage energy conversion, can achieve much higher energy recovery efficiency and simpler power circuit topology, since many renewable DGs, energy storing systems (ESSs) [5], and an increasing number of loads directly utilize DC power. Additionally, the DC system offers improved controllability the complex synchronization, and the reactive power compensation control problems 
intrinsic to the AC grid can be ignored [6, 7]. Furthermore, the DC micro-grid can be fully decoupled from the utility grid by an interface converter, enabling the seamless transition between grid-connected and islanded operation modes [8-10].

Because of the aforementioned methods, the DC microgrid is receiving increased attention, especially for smallscale commercial and residential applications [11]. For AC and DC micro-grids, energy management control is the crucial points. The control objective is coordinating the distributed micro-grid terminals and to provide a simple, reliable, stable, and cost-effective power supply for both local customers and the utility. Much research has been done to develop a standardized hierarchical power management framework [12-14].

Considering the merits and demerits of the AC and DC micro-grid system, we found that very few papers describe the application of DC micro-grid architecture in ERBTS, Especially the energy saving issues for massive gridconnected battery testing system in industry. Hence, this paper proposes a DC micro-grid system based on ERBTS, and the proposed system resolves the above drawbacks. In the proposed system, the converter for battery testing can be designed as a single-stage current-feed DC/DC converter for charging and discharging test experiment, and all the testing instruments share the same DC-bus. To compensate or absorb the additional energy, an energy storing system is configured in the proposed scheme, thus, a DC-microgrid system is formed $[15,16]$. In this way, the recovered energy can be reused for other local loads, which increase the system efficiency and simplify the control strategy for a DC-micro-grid.

This paper is arranged as follows: In Section 2, we will explain the system configuration of conventional ERBTS using AC micro-grid. In Section 3, the system configuration of a DC micro-grid for ERBTS is illustrated. The energy distribution chart comparisons between the conventional $\mathrm{AC}$ and proposed $\mathrm{DC}$ micro-grids under various conditions are elaborated. In Section 4, an optimal energy management control scheme is presented. The corresponding experimental results are also presented. Finally, in Section 5, the main contributions of this paper are summarized and suggested future works are presented.

\section{System Configuration of Conventional Energy Recovery Battery Testing System}

\subsection{System configuration}

In this section, we first illustrate the system configuration of the conventional massive AC-grid-connected ERBTS, and the corresponding control strategies. Drawbacks of the conventional AC-grid are also shown.

Fig. 1 demonstrates the system configuration of the conventional ERBTS, in which the red line represents the utility grid. The black line symbolizes the local micro-grid (AC380V), dividing the testing area into two sections. The high-power testing instruments are connected to the three-phase high AC-voltage (380VAC) side, and relatively low-power test instruments are interconnected on the single-phase (220VAC) side. Each ERBTS contains a bidirectional AC-DC-DC converter and the series connected power battery packs. In this configuration, all the testing instruments are connected in parallel, which form an ACmicro-grid.

The battery testing instrument in Fig. 1 is composed of a bidirectional AC-DC and DC-DC converter which fulfills the battery testing and energy recovery requirements, simultaneously. The discharged energy generated during the testing experiment is reutilized by other testing systems sharing the same AC-grid.

\subsection{Control strategy analysis for AC micro-grid}

Fig. 1 shows the two AC micro-grid systems, namely, the AC380 and AC220V systems. The popular methods for generating voltage/current reference signals for power electronics converter in an $\mathrm{AC}$-grid are mentioned below.

(1) The first method uses a master-slave controller, in which a master controller is used to communicate with all sources using a fast communication technique. All sources (grid-connected converters) inform the master controller of the current status of their local variables (such as voltage/current, frequency, etc.). Based on that information, the master controller computes and transmits the reference voltage/current and frequency values for all the sources. The requirement of a fast communication technique increases the cost of the whole system. Moreover, the reliability of the system is reduced due to the presence of a communication circuit and the master controller [17].

(2) The second method uses a droop controller and measures only the local variables of a source to calculate the reference/current signal of the power converter. This decentralized control scheme does not need a fast communication system between grid-connected converters for operation and has the merits of high reliability, low cost, and easy scalability. Because of these advantages, droop control is extensively adopted in AC micro-grids.

Compared with the AC micro-grid, the DC micro-grid has many advantages. First, it does not require synchronous or frequency tracking control and so is more reliable, controllable, and suitable for distributed generation (DG). Secondly, in DC micro-grid systems, compared with a cascaded power converter, the topology of the one-stage power converter is much simpler, resulting in much higher energy recovery efficiency. Thirdly, the load voltage is not influenced by voltage regulation, voltage dropdown, or 


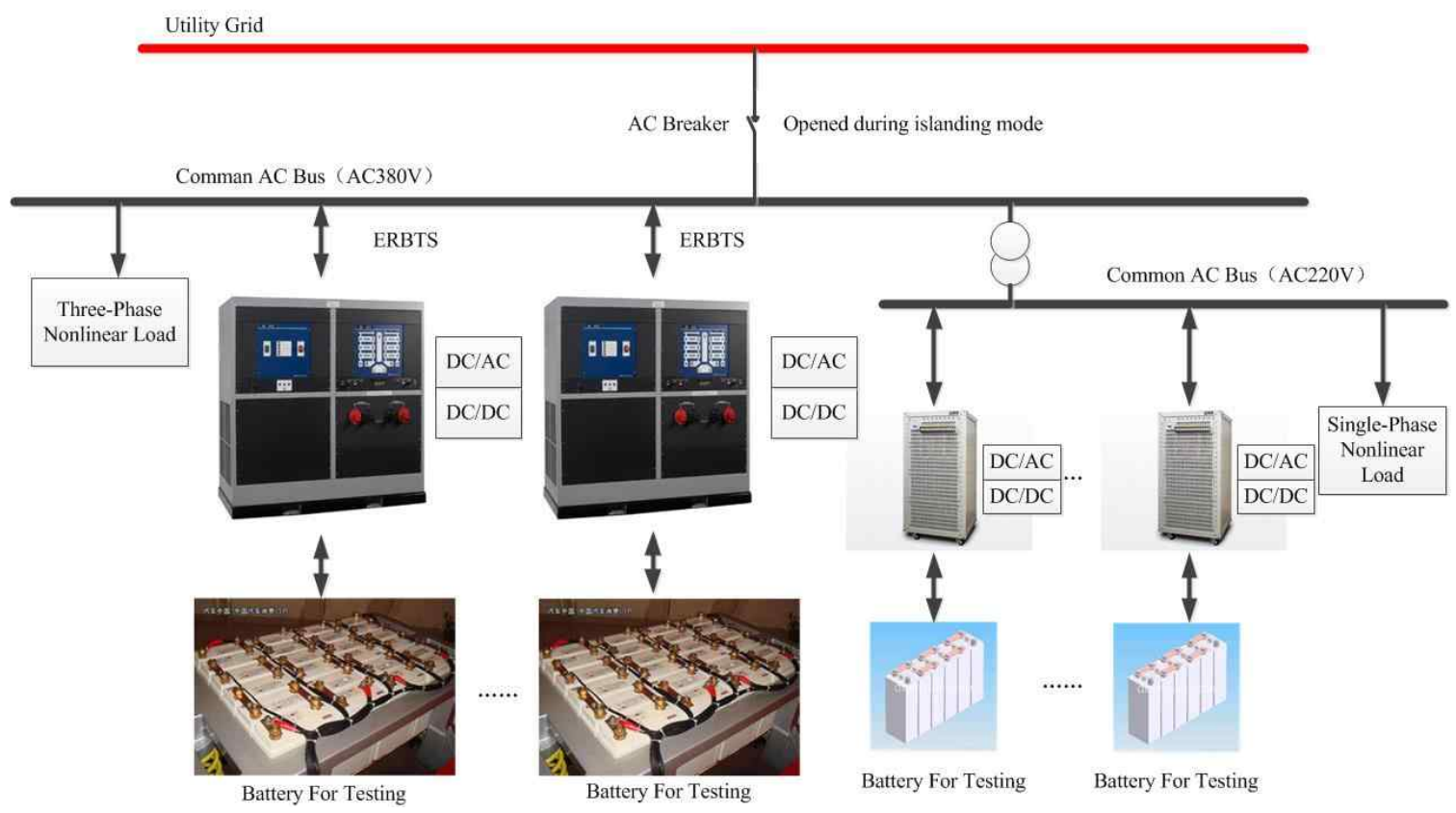

Fig. 1. System configuration of conventional AC grid-connected ERBTS

unbalanced loads. Finally, the DC-voltage in transmission is not influenced by the impulse current; thus, there is no need to consider the line reactive power component, and the line power loss can be ignored. Therefore, combining a DC micro-grid with an AC micro-grid to form a DC microgrid can solve the efficiency and energy balance problems for ERBTS.

\subsection{Energy consumption analysis}

In this section, we will analyze the energy consumption of the ERBTS shown in Fig. 1. In Fig. 2, assuming that battery pack 1 is performing discharging testing and battery pack 2 is performing charging test, so the testing energy released from battery pack 1 is reutilized in battery pack 2 through four stage converters, namely, DC-DC, DC$\mathrm{AC}, \mathrm{DC}-\mathrm{DC}$ and AC-DC converter. Hence, it can be clearly concluded that a very low energy re-utility is implemented in conventional scheme. Much energy is consumed between the power converters. Supposing that the converter's efficiency (and ERBTS-2) are $\eta_{1}$ (DC-DC converter) and $\eta_{2}$ (DC-AC converter) for ERBTS- $1, \eta_{3}$ and $\eta_{4}$ for ERBTS-2, respectively. The total efficiency $\eta$ would be

$$
\eta=\eta_{1} \cdot \eta_{2} \cdot \eta_{3} \cdot \eta_{4}
$$

From the aforementioned analysis, we know that ways that can maximally reduce the energy conversion stages are the only solution to improve the energy re-utility efficiency. DC micro-grid, by its nature, would be more suitable for this application. If DC micro-grid is chosen in this circumstance, the efficiency improvements $\Delta \eta$ would be:

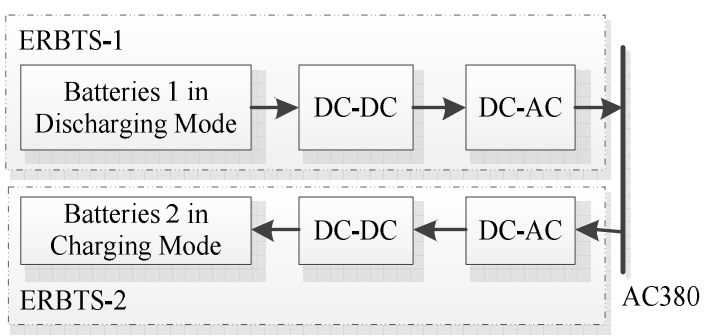

Fig. 2. Energy flow chart among ERBTSs

$$
\Delta \eta=\eta_{1} \cdot \eta_{2} \cdot\left(1-\eta_{3} \cdot \eta_{4}\right)
$$

From Equation (2), massive testing energy can be saved if DC micro-grid based on ERBTS can be adopted.

\section{A DC Micro-grid for Energy Recovery in Power Battery Testing System}

Based on the energy consumption analysis illustrated in section 2.3 , in this section, a DC micro-grid battery testing system is proposed. DC micro-grid system configuration for ERBTS, topology comparisons between the proposed and conventional scheme are elaborated.

\subsection{System configuration}

The configuration of a representative factory is shown in Fig.3, showing that the testing instruments forms a DC micro-grid containing two-level DC-link voltage (high and low DC-link voltage). Large power testing instruments are connected at the high voltage side; the relatively small 


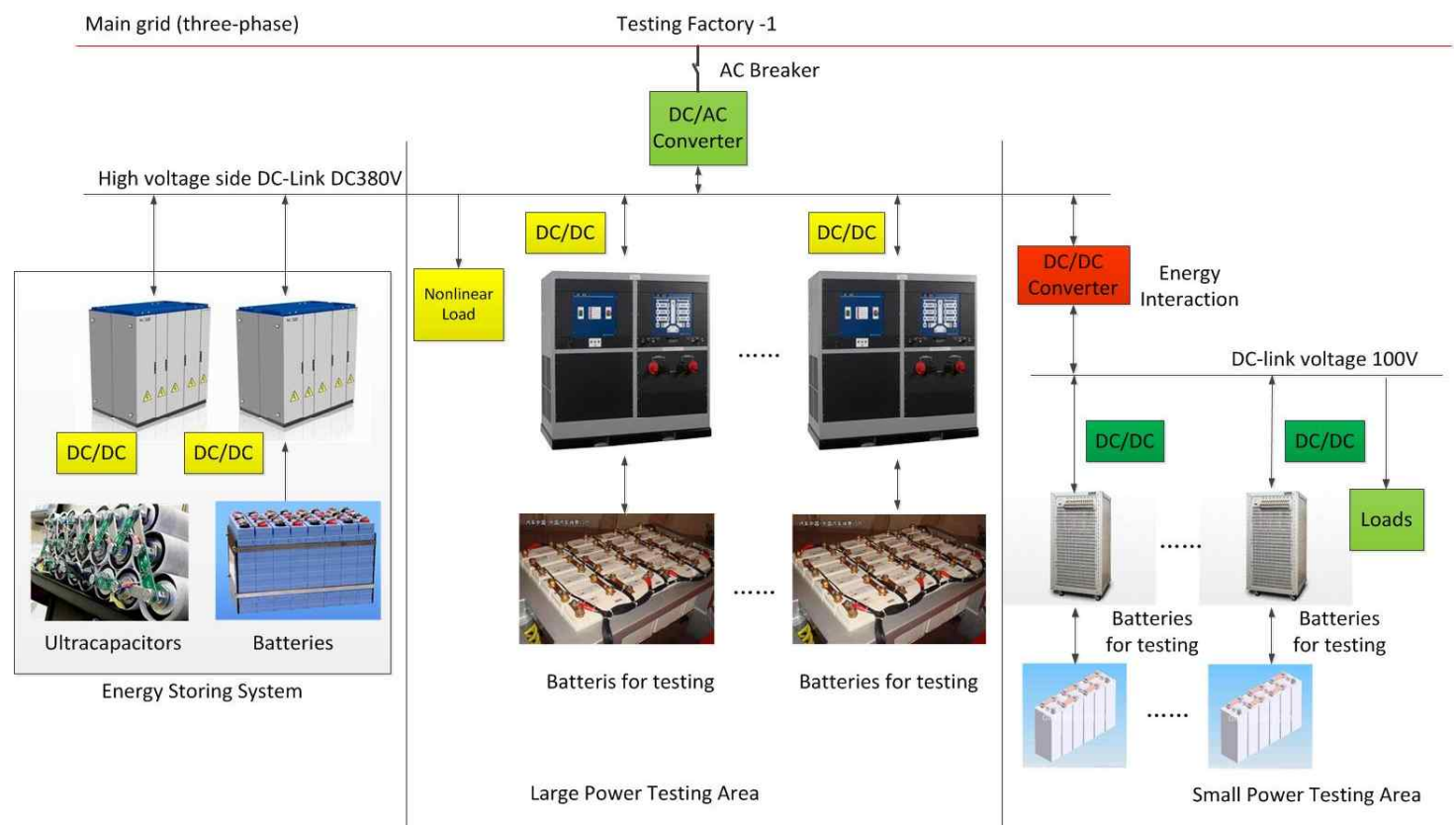

Fig. 3. System configuration of the proposed DC micro-grid for ERABTS

power output testing instruments are connected at the low voltage side. Moreover, a bidirectional DC-DC converter (blue in Fig. 3) is inserted between high and low DC micro-grid for bidirectional energy transmission.

To maintain the stability of the DC-link voltage, an ultracapacitor-battery composite power supply system is adopted in the proposed system, and the energy storing system (ESS) can satisfy both the stable (batteries) and peak power needs (ultra-capacitors), Moreover, the ESS can maintain the stability of DC-link voltage. Since the power converter for testing experiment usually operates as a current-source converter, the operation mode of the DC micro-grid can be dominated by ESS for power balance.

In Fig. 3, a DC/AC converter is preset between the main grid and the DC micro-grid in case the ESS and battery testing instrument reserves are not adequate to meet the power demands for the local loads. In such circumstances, the deficit can be compensated by importing the energy from the utility grid; on the other hand, excess energy reserve of the ESS and battery testing instruments leads to unbalance in the DC-link power, and the additional energy can be exported to the utility. Generally speaking, the DC$\mathrm{AC}$ converter functions as a utility interface converter to maintain the power balance within the micro-grid.

\subsection{Topology comparisons and analysis}

Fig. 4 illustrates the operation principle comparisons between the conventional and proposed schemes used for battery testing instruments. The comparison shows that the proposed scheme has at least three distinct advantages:

(1) In conventional system, the internal power converter topology is composed of DC-DC and DC-AC converters

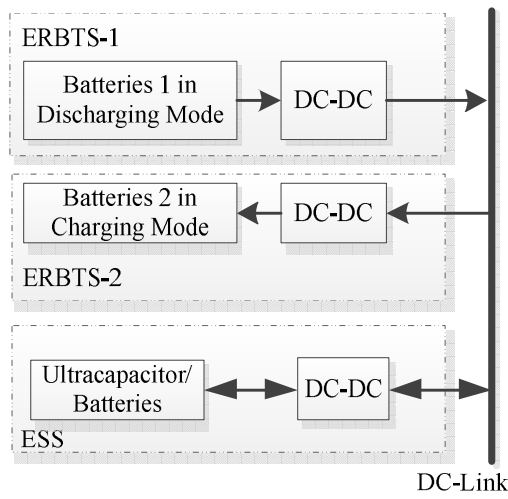

(a)

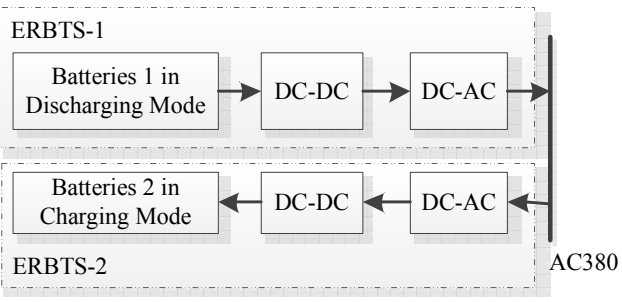

(b)

Fig. 4. Energy routine comparisons between the proposed and conventional scheme: (a) Proposed scheme; (b) Conventional scheme.

connected in series. However, the power converter in the proposed scheme contains only one single stage DC-DC converter, resulting in considerably higher accuracy and energy recovery efficiency. Moreover, since the topology of the converter is greatly simplified, the program work on grid-connected control operations is considerably reduced, and reliability of the testing 
instrument is greatly enhanced.

(2) The inverter in conventional ERBTS is controlled to synchronize with the utility-grid on phase angle, frequency, and amplitude. In addition, in order to eliminate the total harmonic distortion (THD) of the grid-connected inverter, a current filter (such LCL or LC type filter) is usually adopted, requiring complex closed-loop control algorithms. In the proposed scheme, only the DC-link voltage should be maintained stable and constant, resulting in a much simpler structure.

(3) In the proposed scheme, the energy interaction between the testing instruments can be completed in one step (DC micro-grid). However, the conventional scheme needs at least two stages. Hence, the proposed scheme is much simpler.

In addition to the above merits, it is needed to point out that an energy storing system is needed to be configured in the proposed scheme, the ultra-capacitors, by its nature, can compensate the peak the power needs. The power batteries combined with super-capacitors can provide or absorb the constant energy to ensure the stability of the DC-link voltage, which may add extra expense on system.

\section{Energy Management of a DC Micro-grid}

\subsection{Control strategies for ESS}

To mitigate the operation conditions of the batteries in electric vehicle, several testing modes should be done: (a) constant current test; (b) constant voltage test; (c) constant power testing. Hence, each battery for testing may have various test modes.

The ESS is configured in the proposed scheme to ensure the stability of the DC-link voltage in DC micro-grid; hence, a voltage-current double closed-loop control strategy is implemented. Block diagram of the control strategies is illustrated in Fig. 5.

When the DC-link voltage is higher than the reference dc-link voltage, the additional energy should be stored in the ESS; on the other hand, the energy is released from the ESS.

\subsection{Control strategies for ERBTS}

In utility, some ERBTSs performs constant charging test

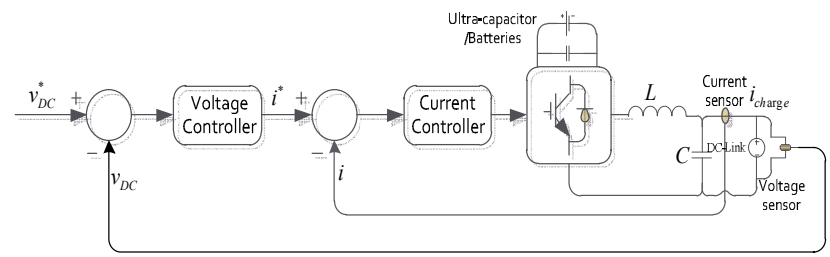

Fig. 5. Control strategies for ESS in the proposed scheme

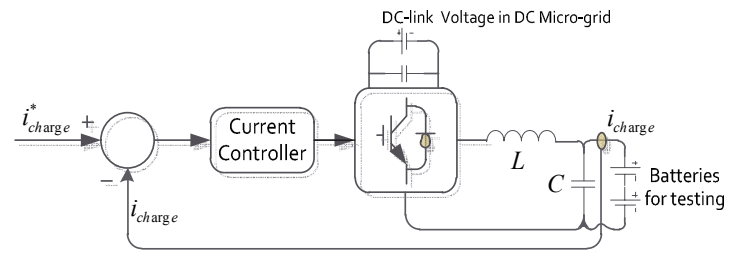

(a) Constant current mode in charging test

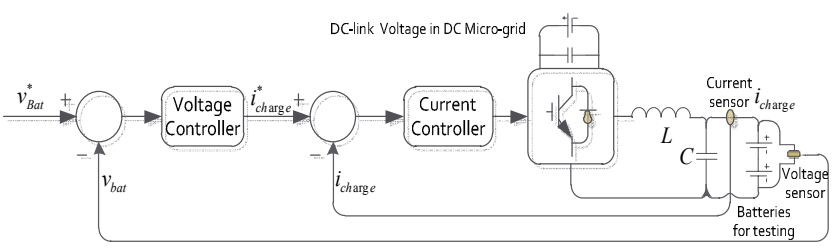

(b) Constant voltage mode in charging test

Fig. 6. Control strategies for ESS in the proposed scheme

experiment, others performs constant discharging test experiment. The control strategies for voltage and current charging testing are illustrated in (a) and (b) in Fig. 6, respectively. The converter in Fig. 6(a) operates as a buck chopper, thus, a current closed-loop system is implemented. In constant voltage (CV) testing mode, as is shown in Fig. 6(b), a voltage-current double closed-loop system is implemented. The current controller is designed to prevent the batteries from overcharging.

In discharging test mode, the testing energy is released to the DC-bus, which can be reused by other batteries performing charging test or stored by ESS via a DC-DC converter. In this way, the energy is efficiently recycled.

\section{Experimental Verification}

\subsection{Hardware platform setup}

To verify the feasibility and validity of the proposed scheme, a scaled-down laboratory prototype of a threenode, three-branch DC micro-grid is developed. The schematic diagram of this system is illustrated in Fig. 3, in which each micro-source converter is a bidirectional DCDC converter. Parameter specifications of the bidirectional DC-DC and AC-DC converters are given in Table 1 and Table 2, respectively. The fast speed micro-processor chosen for voltage and current controller's implementation in charging and discharging test experiment is TMS320F28335 from Texas Instruments.

The experimental hardware setup for the proposed hybrid AC-DC micro-grid contains four parts (Refer to Table 1: (1) The utility grid that contains a three-phase VSC with fundamental frequency isolation transformer, (2) Two bidirectional DC-DC converters for ESS system, (3) Two bidirectional DC-DC converters for battery testing system; one for charging, another for discharging, and (4) two large power resistors for load emulation. 
Table 1. List of the terminals used in experiments

\begin{tabular}{c|l|c|c}
\hline $\begin{array}{c}\text { Energy } \\
\text { source }\end{array}$ & \multicolumn{1}{|c|}{ Compositions } & Power & Number \\
\hline Utility grid & $\begin{array}{l}\text { Three-phase voltage source inverter } \\
\text { with isolation transformer }\end{array}$ & $30 \mathrm{~kW}$ & 1 \\
\hline ESS & $\begin{array}{l}\text { Bidirectional DC-DC converter for } \\
\text { batteries and ultra-capacitors }\end{array}$ & $5.0 \mathrm{~kW}$ & 2 \\
\hline ERBTS & Bidirectional DC-DC converter & $15 \mathrm{~kW}$ & 2 \\
\hline Load & Power resistor & $3 \mathrm{~kW}$ & 2 \\
\hline
\end{tabular}

Table 2. Voltage range definition in each operation mode

\begin{tabular}{c|c|c}
\hline $\begin{array}{c}\text { Operation } \\
\text { mode }\end{array}$ & $\begin{array}{c}\text { Utility dominating } \\
\text { (Mode 1) }\end{array}$ & $\begin{array}{c}\text { ESS dominating } \\
\text { (Mode 2) }\end{array}$ \\
\hline DC-bus voltage & $<200$ & $200 \sim 250 \mathrm{~V}$ \\
\hline
\end{tabular}

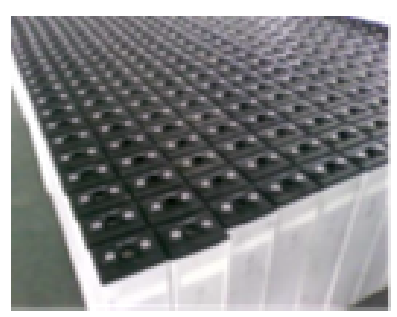

(a)

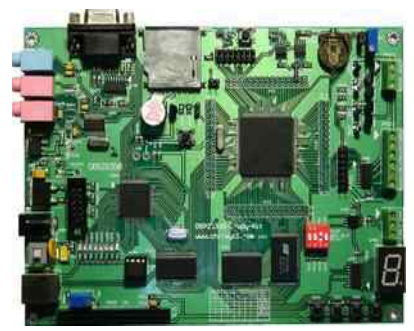

(c)

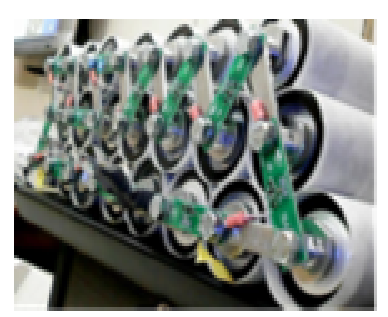

(b)

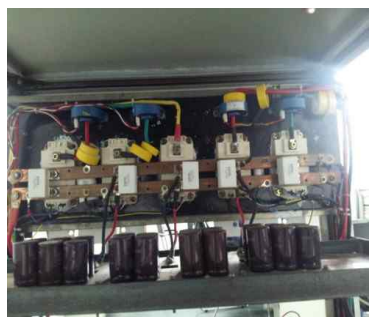

(d)
Fig. 7. Hardware setup of the proposed DC hybrid microgrid: (a) Batteries for testing; (b) Ultra-capacitors for ESS; (c). DSP control board; (d) Bidirectional AC-DC converter.

For safety consideration, the conventional $380-\mathrm{V}$ threephase AC distribution system is reduced to a $75-\mathrm{V}$ threephase AC-grid using a step-down transformer; the DC bus voltage of the tested DC micro-grid system is set between 200 and $250 \mathrm{~V}$. The corresponding voltage of each operation mode is allocated within this range. The thresholds of the DC bus voltage range are listed in Table 2.

\subsection{Experimental results and analysis}

In section 4.1, when the DC-link voltage falls below the lower voltage limit, it can be dominated by the utility grid via a three-phase voltage-source-converter (VSC) that operating as a PWM (Pulse Width Modulation) rectifier. Fig. 8(a) illustrates the waveforms of active and reactive current components when the DC micro-grid is interfacing with the utility grid using unit power factor control (PFC). Fig. 8(b) shows the phase voltage and phase current of the

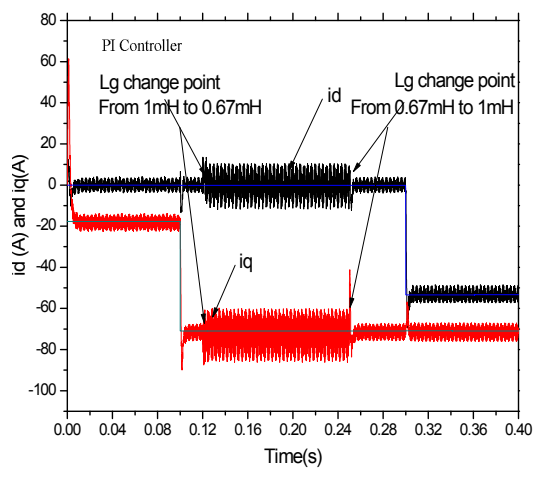

(a)

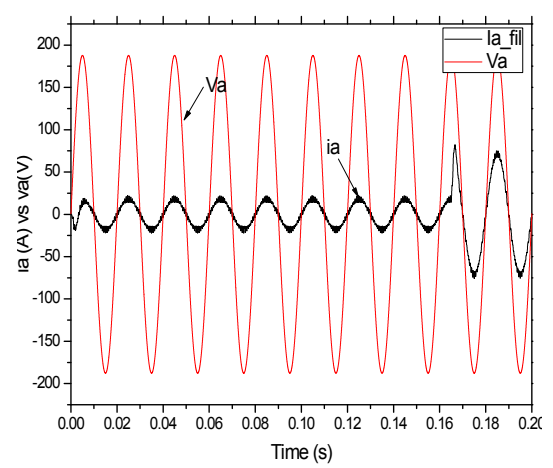

(b)

Fig. 8. (a) Waveforms of the active and reactive current components when the DC micro-grid is interfacing with the AC-grid. (b) Waveforms of the voltage and current at the point of common coupling.

VSC rectifier when there is a deficit in power needs in the DC micro-grid. By dynamically controlling the reactive current component, the DC-link voltage is maintained stable.

Fig. 9(a) illustrates the waveform of the DC-AC converter switching from grid-connected mode to rectifier mode. Grid-connected mode is implemented when the ESS is fully charged and there is additional energy on the DC micro-grid. Rectifier mode is implemented when a power deficit occurs, the grid-connected mode will automatically change to rectifier mode, and the utility will compensate the power needs. Fig. 9(b) demonstrates the transition procedure of the three-phase AC-DC converter operating from grid connected mode to islanded mode.

Fig. 10(a) shows the transition process of the utility grid dominating from islanded mode to grid connected mode. The batteries' charging current controlled by the DC-DC converter is illustrated in Fig. 10(b), showing that the dominating mode changes from utility-dominating mode to ESS-dominating mode. In this case, the DC-bus voltage $v_{\text {dcbus }}$ is greater than the upper limit of the reference voltage vupper $\left(v_{\text {dcbus }}>v_{\text {upper }}\right)$, implying sufficient power output in the DC-link. This additional energy will automatically charge the capacitors and increase the DC-bus voltage, ultimately resulting in a high voltage breakdown. Therefore, 


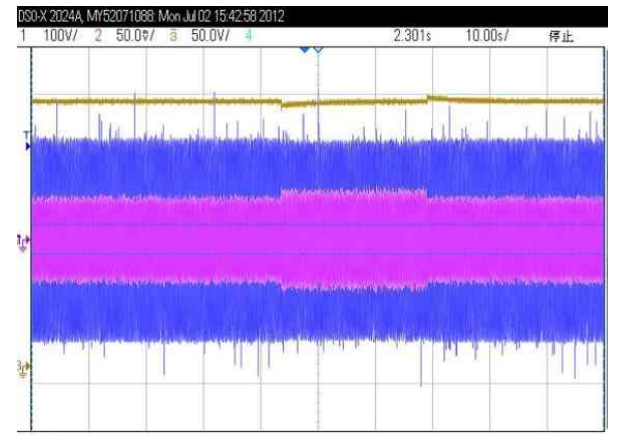

(a)

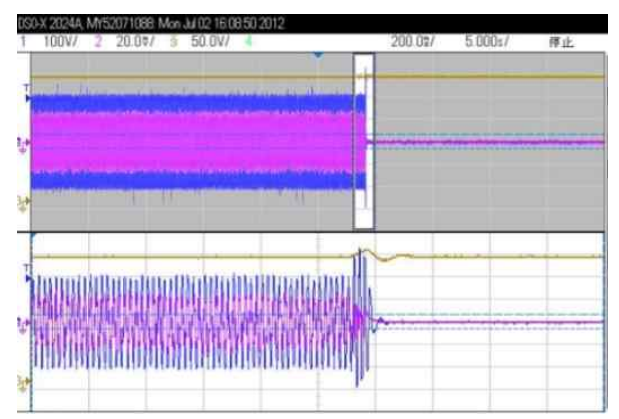

(b)

Fig. 9. (a) The waveform of the converter transiting from grid-connected mode to rectifier mode: (b) The waveform of the converter transiting from gridconnected mode to islanded operation mode.

in order to release the additional energy, the operating mode of ESS should be changed from discharging to charging control. Fig. 10(b) shows the waveform results of the mode transition when the batteries' testing current changes from $+20 \mathrm{~A}$ (discharging current) to $-20 \mathrm{~A}$ (charging current). The experimental results show that the proposed scheme is feasible and applicable.

From the aforementioned experimental results, compared with conventional scheme, two energy conversion stages (AD-DC and DC-AC converter) are decreased. The efficiency for one AC-DC converter is $92 \%$, as a result, the energy saving percentage in the proposed scheme would be $16 \%$.

\section{Conclusions}

This paper presents an improved system configuration of energy saving system for many battery testing systems using DC micro-grid. Energy chart comparisons between the proposed and conventional schemes under the same operation mode are illustrated. The proposed scheme can greatly enhance the energy saving efficiency by way of maximally reducing the redundant energy conversion stages. Based on the theoretical analysis, the control strategies for utility grid, ESS and ERBTS are elaborated, respectively. A laboratory small power DC micro-grid

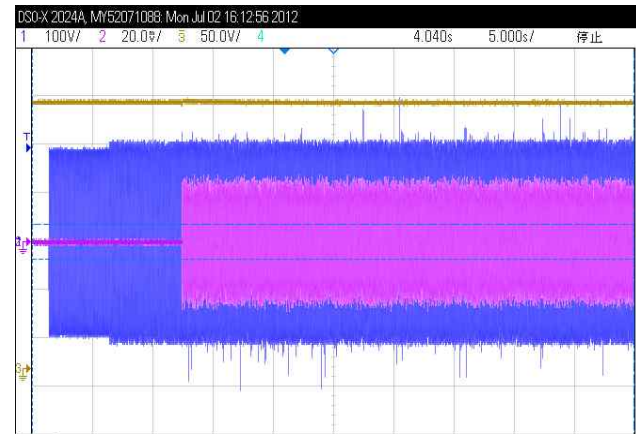

(a)

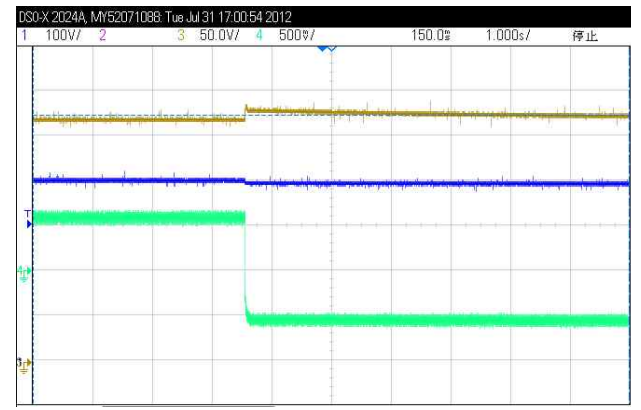

(b)

Fig. 10. (a) The waveform of the DC-AC converter transiting from islanded mode to grid-connected mode; (b) Waveform of the charging current for the DC-DC converter.

system for ERBTS is setup for verifications. The experimental results demonstrate that the proposed scheme is not only valid but also applicable.

Due to the high efficiency on energy recovery and energy reutilizing features, the proposed scheme is of great importance and can be directly applied to battery or ultracapacitor manufactures for testing requirements.

\section{Acknowledgements}

This paper was supported by research funds of Chonbuk National University in 2011.

\section{References}

[1] Bo. Long, Chong. K.T. "Parameter Design and Power Flow Control of Energy Recovery Power Accumulator Battery Pack Testing System," J Electr Eng Technol, vol.8, pp.787-798, 2013.

[2] Long. Bo. Ryu. J. H. Lim. S.T and Chong. K.T. "Design and Control of a Multi-Functional Energy Recovery Power Accumulator Battery Pack Testing System for Electric Vehicles," Energies, vol.7, pp. 1376-1392, 2014.

[3] Long. Bo, Kil. T. C. "Modeling and Direct Power 
Control of Energy Recovery Power Battery Testing System under Charging Mode - A New Approach," Int Rev Electr Eng-I vol. 7, pp.5993-6004, 2012.

[4] Long, Bo, Ryu. J.H, Chong. K.T. "Optimal Switching Table-Based Sliding Mode Control of an Energy Recovery Li-Ion Power Accumulator Battery Pack Testing System," Energies, vol. 6, pp. 5200-5218, 2013.

[5] Yunjie.G, Xin.X, Wuhua L and Xiangning. "H. Mode-Adaptive Decentralized Control for Renewable DC Micro-grid With Enhanced Reliability and Flexibility," IEEE Transactions on Power Electronics, vol. 29, pp. 5072-5080, 2014.

[6] Eghtedarpour. N, Farjah, "E. Power Control and Management in a Hybrid AC/DC Micro-grid," IEEE Transactions on Smart Grid, vol. 5, pp.1494-1505, 2014.

[7] Loh. P.C. Ding, L.Yi Kang. And C. Blaabjerg. F. "Autonomous Operation of Hybrid Micro-grid With AC and DC Subgrids," IEEE Transactions on Power Electronics, 28, pp. 2214-2223, 2013.

[8] Blaabjerg. F. Teodorescu.R,Liserre. M and Timbus, A.V. "Overview of Control and Grid Synchronization for Distributed Power Generation Systems," IEEE Tr ans on Industry Electronics, vol. 53, pp.1398-1409, 2006.

[9] Rocabert. J, Luna. A, Blaabjerg. F and Rodriguez. P. "Control of Power Converters in AC Micro-grid,". IE EE Transactions on Power Electronics, vol, 27, pp. 4734-4749, 2012.

[10] He. J. W, Li. Y. W and Munir, M. S. "A Flexible Harmonic Control Approach through VoltageControlled DG-Grid Interfacing Converters," IEEE T ransactions on Industry Electronics, vol. 59, pp. 444-455, 2012.

[11] Kakigano, H, Miura, Y. Ise. T. "Low-Voltage Bipolar-Type DC Micro-grid for Super High Quality Distribution," IEEE Transactions on Power Electron ics, vol. 25, 3066-3075, 2010.

[12] Guerrero, J.M, Loh, P.C, Lee, T.L and Chandorkar, M. "Advanced Control Architectures for Intelligent Micro-grids-Part II: Power Quality, Energy Storage, and AC/DC Micro-grids," IEEE Transactions on Ind ustry Electronics, vol. 60, pp.1263-1270, 2013.

[13] Guerrero. J.M, Chandorkar, M, Lee, T.L and Loh, P.C. Advanced Control Architectures for Intelligent Micro-grids-Part I: Decentralized and Hierarchical Control. IEEE Transactions on Industry Electronics vol. 60, pp.1254-1262, 2013.

[14] Kim. J, Guerrero. J. M, Rodriguez. P, Teodorescu, $\mathrm{R}$ and Na. K. "Mode Adaptive Droop Control with Virtual Output Impedances for an Inverter-Based Flexible AC Micro-grid," IEEE Transactions on Power Electronics, vol.26, pp.689-701, 2011.

[15] Sanchez. S, Molinas. M, Degano, M and Zanchetta. P. "Stability evaluation of a DC micro-grid and future interconnection to an AC system," Renewable Energy, vol. 62, pp.649-656, 2014.

[16] Hemmati. M, Amjady. N and Ehsan. M. "System modeling and optimization for islanded micro-grid using multi-cross learning-based chaotic differential evolution algorithm," International Journal of Elec tric Power and System, vol. 56, pp.349-360, 2014.

[17] Anand.S, Fernandes B.G. "Reduced-Order Model and Stability Analysis of Low-Voltage DC Microgrid," IEEE Transactions on Industrial Electronics, v ol. 60, pp.5040-5049, 2013.

[18] Ito. Y, Zhongqing. Y and Akagi. H. "In DC microgrid based distribution power generation system," Power Electronics and Motion Control Conference, 2004. IPEMC 2004. The 4th International, 14-16 Aug 2004, pp. 1740-1745.

[19] Lie. X, Dong. C. "Control and Operation of a DC Micro-grid With Variable Generation and Energy Storage," IEEE Transactions on Power Delivery, vol. 26, pp.2513-2522, 2011.

[20] Rodriguez, M.; Stahl, G.; Corradini, L.; Maksimovic, D. "Smart DC Power Management System Based on Software-Configurable Power Modules," IEEE Transactions on Power Electronics, vol. 28, pp. 1571-1586, 2013.

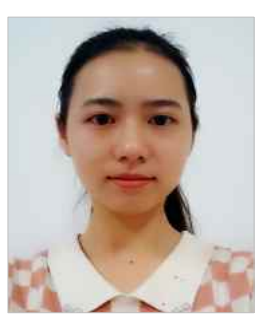

Ke Zhang was born in Hubei province, China, in 1993. She received her B.S. Degree in Electrical Engineering from Hubei University of Technology, Wuhan, China in 2015; She is currently working toward her M.S. Degree in Power Electronics and Electrical Drive at University of Electronic Science and Technology, Chengdu, China. Her research interests include energy internet, energy router and grid-connected inverter.

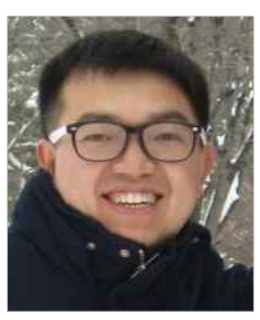

Long Bo received B.S. and M.S. degrees from Petroleum University, Xian, in 2001 and 2004, then, received his Ph.D. from Xi'an Jiao Tong University in June 2008. He is currently an assosciate professor in the school of Mechatronic Engineering at the University of Electronic Science and Technology of China, in Cheng Du. His current research interests include high-performance motor drives, renewable energy generation, distributed generation systems, microgrid, and unified power quality conditioners. He is currently doing post doctorate work in the Department of Electric and Information Engineering at Chonbuk National University, Jeonju, in South Korea. 


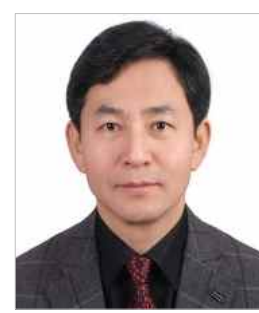

Cheol-Jung Yoo received B.S. degree in Computer Science and Statistics from Chonbuk National University, Jeonju, Korea in 1982, then, M.S. degree in Computer Science and Statistics from Chonnam National University, Kwangju, Korea in 1985, and then, Ph. D. degree in Computer Science and Statistics from Chonbuk National University, Jeonju, Korea in 1994. He was a visiting professor in EECS at the University of California Irvine from January 2012 to July 2013. He is currently a professor in the Department of Software Engineering, Chonbuk National University, Jeonju, Korea. He is also the Associate Chair of Korea Information Processing Society. His current research interests include interoperability testing of embedded system and software, multimedia system and software, software quality and testing, etc.

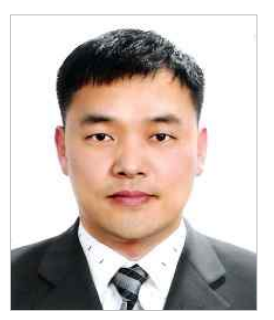

Hye-Min Noh received B.S. degree, M.S. degree and Ph.D. from Chonbuk National University, Republic of Korea. $\mathrm{He}$ is currently a visiting full-time instructor in the department of Software Engineering at the Chonbuk National University, Republic of Korea. His current research interests include software architecture, software testing, embedded system, software development process, software design methodology and IoT.

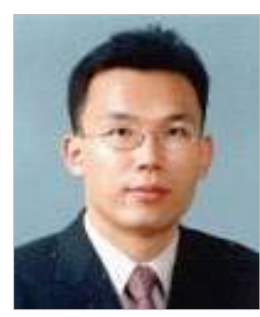

Young Won Chang received the Ph.D. degree in computer engineering from Chonbuk National University, Jeonju, Republic of Korea. Currently, he is a founder of SSL. Inc. His research interest are in the areas of robotics, neural network, power electronics, software engineering, vision processing,

and system testing. 